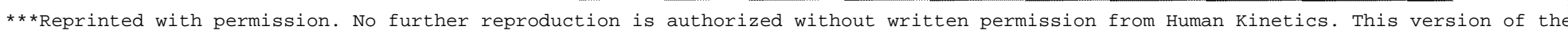

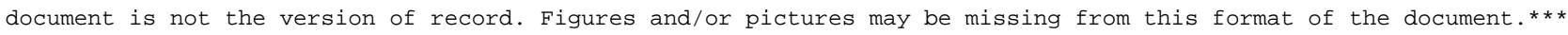

\title{
Provision of Feedback to Students, Part l: Overview of Strategies
}

Sara Nottingham, MS, ATC, CSCS and Jolene Henning, EdD, ATC • University of North Carolina at Greensboro

$\mathrm{T}$ he relationship between an Approved Clinical Instructor $(\mathrm{ACl})$ and athletic training students creates a unique instructional interaction. A low instructor-to-student ratio allows an ACI to regularly provide feedback to students about the status of their clinical skills. This feedback of student perfor-

\section{KEY POINTS}

Feedback is an informal type of waluation that focuses on providing infomation to improve future performance.

Approved dinical instnuctors con improve student skills and dinical reasaging by providing feedback. mance, whether it is confirming, correcting, or providing suggestions for change, can be given in many ways, such as written notes, verbal comments, or nonverbal communication (e.g., a nod of the head). ${ }^{1,2}$ An additional way to provide feedback is with the use of Clinical Encounter Cards (CECS). CECs are small (i.e., the size of an index card), user-friendly feedback cards that provide a way for instructors to give valuable and efficient information to students about their clinical performances. ${ }^{3}$ Part 1 of this two-part report addresses effective feedback, types of feedback, and how feedback is used in clinical education. Part 2 will provide examples of CECs and discuss ways in which they can be used in athletic training clinical education.

\section{Feedback in General}

Feedback serves as a guide to students in developing their clinical skills, which is an essential part of clinical education. By reinforcing correct behaviors and correcting mistakes, feedback helps students understand what information they know and where they need to improve. ${ }^{2}$ Without feedback, a student often remains unaware of the level of his or her clinical competence, which can potentially lead to incorrect performance of skills necessary for patient care. ACls should use feedback to correct and reinforce professional behaviors and communication skills, in addition to psychomotor skills and knowledge. ${ }^{4}$

In general, feedback is an informal type of evaluation that focuses on providing information to improve future performance. ${ }^{2}$ It is formative and typically involves less judgment than more formal summative evaluation. $^{2}$ Although there is less emphasis on scoring or grading performance when giving feedback, students still need an understanding of the accuracy of their performances in order to improve. Therefore, there must be some degree of assessment when giving feedback. Although distinctions between feedback, assessment, and evaluation are not always clearly delineated. ACIs should 
remember to focus on providing information rather than scoring a student when giving feedback.

Authors in general education. medicine, and ath.. letic training have suggested effective uses of feedback. ${ }^{1,2.5}$ Specific feedback is not synonymous with general praise. Specific feedback provides detailed suggestions to a student concerning performance and how it can be improved in the future. ${ }^{5}$ Information about the process of completing a task, not just the outcome, is important. ${ }^{6}$ For example, commenting on the student's use of patient responses to injury history questions and hand placement during an orthopedic physical examination is much more helpful than just stating whether the assessment was correct or incorrect. Providing feedback that is immediate, rather than delayed by hours or days, improves retention of the information. ${ }^{2,5}$ Immediate feedback should always be given if the student's behaviors could cause harm to a patient. For example, if a student evaluating an acute ankle injury attempts to have an athlete bear weight before ruling out a fracture, the $\mathrm{ACl}$ must intervene to prevent further injury to the patient. Provision of feedback should be established as a regular occurrence so that communication with students is always maintained. ${ }^{2}$

Effective feedback should also include active participation of the student. It should initiate a conversation between the student and $\mathrm{ACl}$ and hopefully will lead to mutual agreement about the student's performance and a plan for improvement. ${ }^{2}$ When reviewing a student's plan for a patient's rehabilitation session, an ACl determines that the student's plan is too aggressive. Before providing comments to the student, the $\mathrm{ACl}$ should ask the student to assess the plan and identify areas of concern. The ACI can then provide feedback to the student, and they can discuss how the student can improve the rehabilitation plan before the patient's rehabilitation session begins. A diagram of the feedback loop that should occur between an $\mathrm{ACl}$ and a student is presented in Figure 1.

\section{Types of Feedback}

The type of feedback provided will depend on the educational level and personality of the student. ${ }^{7}$ Correc. tive feedback, which focuses on correct performance of a skill, is most appropriate for novice students who are developing basic skills. In contrast, directive feedback helps students to consider different treatment options and possibilities for improvements in future performance of a skill. ${ }^{7}$ For example, a student may select Russian neuromuscular electrical stimulation current to reduce an athlete's low back muscle spasm. Corrective feedback may include statements like the following: "Russian current could be used, but it is typically a very uncomfortable treatment. Let's use a symmetrical biphasic current instead." Directive feedback would involve verbal guidance like the following: "Although

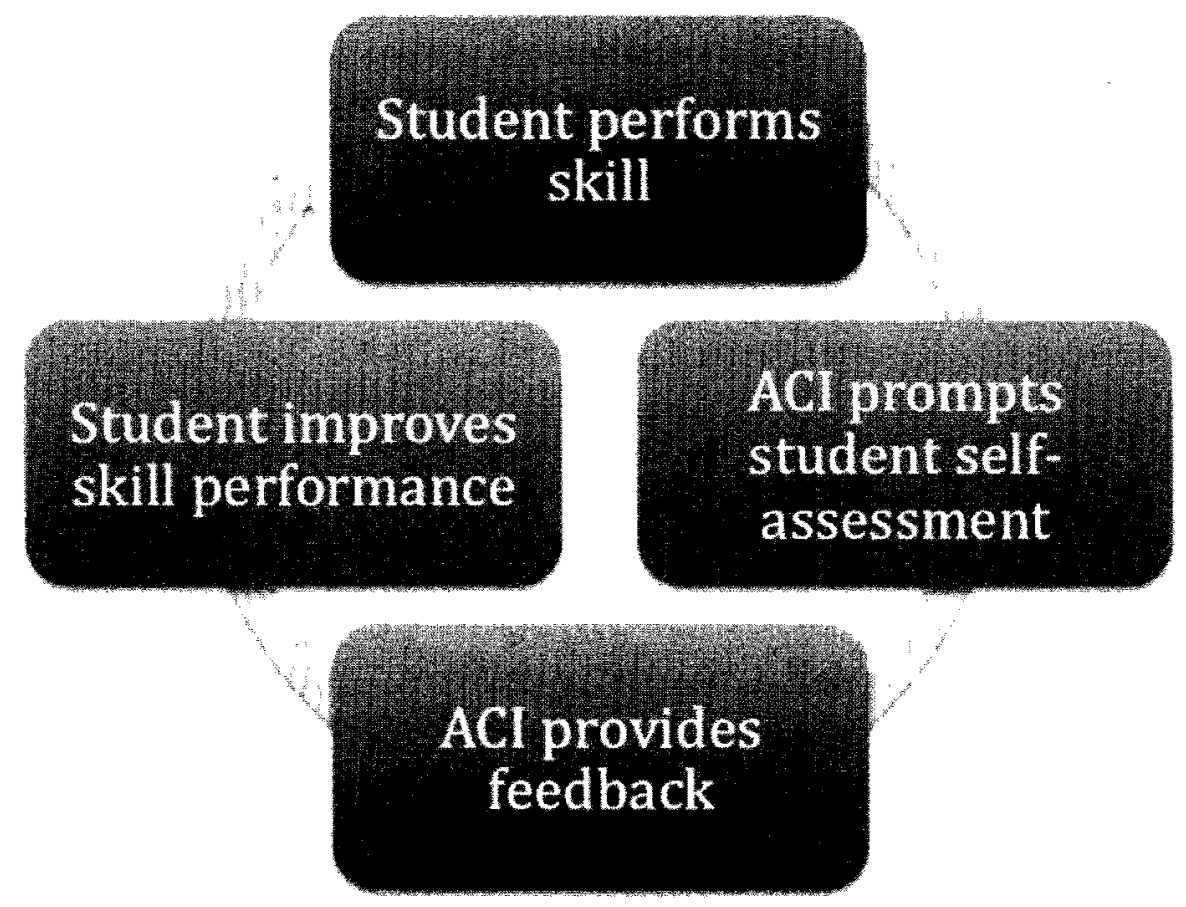

Figure 1 Feedback loop of student skill performance. 
this current can be used to decrease muscle spasm, it is usually not very comfortable for the patient. What other currents could you use to achieve the treatment goal and why?"

An insecure student may require greater praise than a more confident student in the process of correcting a skill. Comments from the $\mathrm{ACl}$ should be focused on modifiable behaviors, rather than personality characteristics, to help maintain a student's self-esteem. ${ }^{2.4}$ For example, an ACI who observes a novice student having difficulty in providing verbal instructions to a patient performing a D1 PNF pattern for the shoulder might praise the student for knowing the correct movement pattern before providing instructions for improved synchronization of verbal cues with manual guidance. Providing feedback in a harsh tone, or making negative comments in front of patients or other students, may be insulting to a student. An ACl should be conscious of how and when feedback is provided. ${ }^{1,4}$

\section{Summary}

Feedback is an important part of an athletic training student's clinical education. Without appropriate feedback, students may make incorrect assumptions about clinical competence, and they have little guidance for improvement of future performances. Feedback that is specific, process-oriented, frequent, immediate, and presented in a manner that facilitates two-way communication with the student provides the greatest benefits. Feedback should be more focused on providing information for future improvements, rather than judging the quality of a performance.

\section{References}

1. Barnum MG, Guyer S, Levy L, et al. Questioning and feedback in athetic training clinical education. Atht Train Ed J. 2009:4(1):23.27.

2. Ende J. Feedback in clinical medical education. I Am Med Assoc. 1983;250:777-781.

3. Greenberg L. Medical students' perceptions of feedback in a busy ambulatory setting: a descriptive study using a clinical encounter card. South Med J, 2004,97;1174-1178

4. Swann E. Communicating effectively as a clinical instructor. Athl Ther Today $2002 ; 7(5): 28-33$

5. Shute V. Focus on formative feedback. Rev Eauc Res. $2008,78(1): 153$ 189

6. Hattie J, Timperley $\mathrm{H}$. The power of feedback, Rev Educ Res $2007 ; 77(1): 81-112$.

7. Barnum MG, Guyer S, Levy L. et al. The supervision, questioning, feedback model of clinical teaching. In Weidner TG. The Athletic Trainer's Pocket Guide to Clinicat Teaching. Thorofare, NJ: Slack: 2009: 85-99.

Sara Nottingham is a graduate teaching assistant and $\mathrm{ACl}$, and Jolene M. Henning is an associate professor and ATEP Director in the Department of Kinesiology at the University of North Carolina at Greensboro.

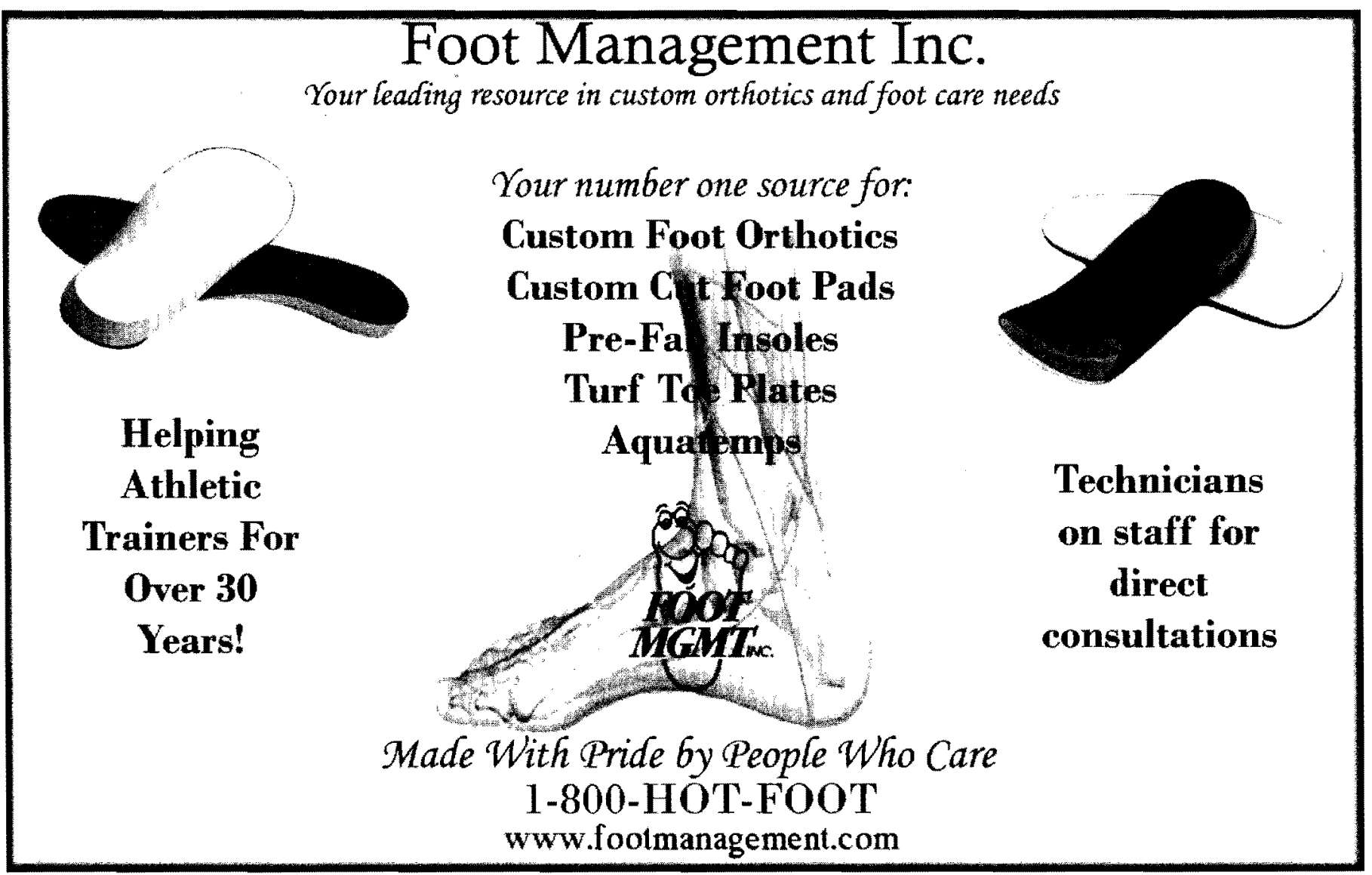

